\title{
Utilization Of Glycerol By Product From Transesterification Of Waste CookingOil As A Cosurfactant In Nanocream Preparation
}

\author{
${ }^{1}$ Zulmai Rani, ${ }^{2}$ Julia Reveny, ${ }^{3}$ Urip Harahap \\ ${ }^{1}$ Postgraduate Programs Faculty of Pharmacy, Universitas Sumatera Utara, Medan, 20155, Indonesia \\ ${ }^{2,3}$ Departement of Technology Formulation, Faculty of Pharmacy, Universitas Sumatera Utara, Medan, \\ 20155, Indonesia \\ *Corresponding author: \\ Email: zulmairani85@yahoo.com
}

\begin{abstract}
.
Waste cooking oil (used cooking oil) is oil derived from leftover cooking oil for frying food. Waste cooking oil is still considered as waste by some people and waste cooking oil that should not be suitable for consumption is sometimes still widely reused in food processing, this can endanger health and reduce the nutritional value of food. In order to be used and have economic value, it is overcome by synthesizing waste cooking oil into glycerol so it can be used as cosurfactant. Besides as cosurfactant, this waste cooking oil glycerol also can be used for various chemical industies, foods, cosmetics, and pharmaceuticals industries. For cosmetic preparation, it can make a nanocream preparation. The purpose of this research was to utilize waste cooking oil into a glycerol which is used as a cosurfactant, to characterize the synthesis results based on $I R$ Spectroscopy data and to formulate it to nanocream preparation. The research was conducted in an experimentally by making glycerol from side product of waste cooking oil. Separating glycerol process conducted by transesterification reaction. Glycerol of waste cooking oil by product was characterized with IR Spectroscopy and evaluated include organoleptic, glycerol contents, density, viscosity, ash content, and moisture content. Formulation of nanocream preparation using $30 \%$ of Tween 80 as surfactant, glycerol by-product as cosurfactant 7,5\% concentration, and $20 \%$ of VCO as oil phase. The nanocream preparation was measured for its particle size with the aim of being able to determine the particle size of the formula to form nanoparticle size. The results showed that glycerol of waste cooking oil by product shows the presence of $\mathrm{OH}, \mathrm{CH}$-aliphatic, $\mathrm{C}=\mathrm{O}$ carbonyl and $\mathrm{C}-\mathrm{O}$. particle size of nanocream preparation obtained was 397,76 $\mathrm{nm}$. Based on the result of this research, the conclusion is glycerol of waste cooking oil byproduct can form nano size with presence of glycerol as cosurfactant. The particle size of the nanocream preparation obtained was still in the nanocream requirement range, namely $20-500 \mathrm{~nm}$.
\end{abstract}

Keywords: Keywords: waste cooking oil , transesterification, glycerol, nanocream

\section{INTRODUCTION}

Waste cooking oil (waste cooking oil) is oil derived from leftover cooking oil for frying food. Waste cooking oil is still considered as waste by some people and waste cooking oil that should not be suitable for consumption is sometimes still widely reused in food processing, this can endanger health and reduce the nutritional value of food. Various exploration carried out to find alternative energy has made utilization waste cooking oil to be sought. Either one as a raw material for biodiesel making (Aziz, 2007). Waste cooking oil (food industry and household waste) can be used as a raw material for glycerol making. The use of waste cooking oil is expected to reduce waste production and increase the selling price of waste cooking oil itself (Aziz et al., 2013).

Glycerol $\left(\mathrm{C}_{3} \mathrm{H}_{8} \mathrm{O}_{3}\right)$ with the chemical name 1,2,3-propanatriol is trihydroxy alcohol, is an organic compound in the form of a thick liquid, colorless, and odorless but tastes sweet, hygroscopic, neutral to litmus (Ditjen POM, 1995). Glycerol is commonly found by-product of biodiesel production from transesterification reaction (M. Pagliaro and Rossi, 2008). In general, the transesterification reaction is the reaction of alcohol with triglycerides to produce methyl esters and glycerol with the help of a base catalyst 
(Julianus, 2006). The alcohols commonly used are methanol and ethanol. This reaction tends to form methyl esters faster than the esterification reaction using an acid catalyst (Arita et al., 2008). The glycerol produced through the transesterification process is expected to be used as an alternative to fulfillment of glycerol needs. Glycerol is also very valuable economically and its use is very wide. Glycerol in large quantities is used in the manufacture of drugs, cosmetics, toothpaste, urethane foam, synthetic resins and others (Appleby, 2005). According to research by Wardana et al., (2019) that glycerol produced from waste cooking oil can reduce the surface tension of water. In pharmaceutical preparations, glycerol is usually used as a cosurfactant. Previous studies using glycerol as a cosurfactant include making preparation of microemulsion gel from a combination of VCO and rice bran oil as a hair fertilizer by using tween $8045 \%$ as a surfactant and $25 \%$ glycerin as a cosurfactant which produces a clear and stable microemulsion (Suhery et al., 2018). According to Priani et al., (2018) also made a preparation of microemulsion gel using glycerin as cosurfactant $35 \%$ which can form a stable microemulsion gel.

Nanocream is one of several innovations in cosmetic delivery system technology. Nanocream is a semisolid preparation, which is a stable emulsion and has a diameter about 20-500 $\mathrm{nm}$. The advantages of nanocream preparations include more active substances that can be formulated in one preparation due to an increase in the solubility capacity of the active substance so that the thermodynamic activity of the active substance on the skin also increases and other advantages are the main components of nanoemulsions in the form of oil phase, water phase, and combinations of surfactant-cosurfactant can be one that can synergistically increase the flux of the active substance (Hermanto, 2016). Cosurfactant is substances that can assist surfactant in reducing the surface tension between the oil phase and the water phase so that it plays a very important role in the stability of the nanoemulsion produced.

\section{METHOD}

\subsection{Sampling}

Material used was waste cooking oil from leftover cooking oil for meal preparation from Z Brand, used for frying 2x obtained from the Sisingamangaraja area of Medan.

\subsection{Manufacture of Glycerol from Waste cooking oil}

\subsubsection{Manufacture Crude Glycerol}

Waste cooking oil is filtered first and $500 \mathrm{~g}$ is taken and then heated up to $110^{\circ} \mathrm{C} . \mathrm{KOH}(5 \mathrm{~g})$ was dissolved in $250 \mathrm{ml}$ of methanol. The waste cooking oil is heated up to $60^{\circ} \mathrm{C}$, a mixture of methanol $\mathrm{KOH}$ is added and stirred for 1 hour with a magnetic stirrer, after that let it stand for approximately 8 hours so that the biodiesel and crude glycerol are separated completely and crude glycerol is separated from biodiesel (Aziz et al., 2008)

\subsubsection{Purification of Crude Glycerol}

Crude Glycerol obtained then added with $3 \mathrm{ml}$ phosphoric acid $\left(\mathrm{H}_{3} \mathrm{PO}_{4}\right) \mathrm{pH}$ up to 6 as desired. The $\mathrm{pH}$ measurement is carried out with a $\mathrm{pH}$ meter, after three layers are formed, the glycerol layer is separated from the other layers, then analyzed for glycerol content. Crude glycerol that has been separated earlier is added $70 \mathrm{ml}$ of water, and activated carbon (4\%). The activated carbon used previously was washed first. The mixture was stirred for 30 minutes and left for 24 hours, after that it was filtered, then evaporated with a rotary evaporator to remove the remaining methanol and water content The sample was put into a rotary evaporator, which had previously been set at a vacuum pressure and a temperature of $60^{\circ} \mathrm{C}$. The bottom product, which is glycerol, was analyzed by FT-IR Spectrophotometry.

\subsection{Evaluation of Glycerol by product of Waste cooking oil}

\subsubsection{Organoleptic Glycerol}

Visual observation of odor, color, shape or consistency, and the presence or absence of phase separation in the glycerol making (Ditjen POM, 1995). Glycerol was put into a vial, stored at room temperature and the stability parameters were measured and evaluated. 


\subsubsection{Determination Density of Glycerol}

Determination density is carried out by weighing an empty pycnometer bottle. After that, the sample is inserted into the pycnometer until it is full and weighed again. Then calculated the density value obtained (Wijaya et al., 2012).

\subsubsection{Determination Viscosity of Glycerol}

Determination Viscosity is carried out by putting glycerol into a beaker and choosing appropriate spindle using Brookfield viscometer (Kaplan et al., 2019).

\subsubsection{Determination of Glycerol Ash Content}

$5 \mathrm{~g}$ of sample was weighed and putted into a porcelain cup that had been dried and the weight was known. Then the cup and sample were burned with an electric heater, until the sample was smokeless and turned into ash in a furnace at $550^{\circ} \mathrm{C}$ until light gray ash was produced or the weight was constant. Then it was cooled again in a desiccator and weighed as soon as it reached room temperature (AOAC, 1995).

Ash content $(\%)=\frac{w_{1}}{w_{2}} \times 100(\%)$

Explanation:

$\mathrm{W} 1=$ Mass of Ash (g)

$\mathrm{W} 2=$ Mass of sample $(\mathrm{g})$

\subsubsection{Determination of Glycerol Water Content}

$5 \mathrm{~g}$ of sample was weighed and putted into a cup that had been dried and the weight was known. Then the samples and cup were dried in an oven at $105^{\circ} \mathrm{C}$ for 3 hours. The cup is cooled and weighed, then dried again until a constant weight is obtained (AOAC, 1995).

$$
\mathrm{KA}=\frac{b-(c-a)}{b} \times 100 \%
$$

Explanation:

$\mathrm{KA}=$ Moisture Content (\%)

$\mathrm{a}=$ Weight of the cup (grams)

$\mathrm{b}=$ sample weight (grams)

$\mathrm{c}=$ weight of cup + sample (after drying)

\subsubsection{Fouier Transform Infrared (FTIR)}

Examination of glycerol with Fouier Transform Infrared Spectroscopy (FTIR). This glycerol test is to determine the similarity of commercial glycerol functional groups with waste cooking oil glycerol. The glycerol test was determined by Fouier Transform Infrared Spectroscopy (FTIR) by identifying the characteristic wave number of glycerol. Radiation from the light source is passed through the interferometer to the sample before it reaches the detector. During signal amplification, high frequencies have been removed by a filter, then the data is converted to digital form by an analog-to-digital converter and transferred to a computer to undergo a Fourier transform (Rohman, 2014).

\subsection{Procedure for Making Preparations of Nanocream}

The process of making preparations of nanocream begins with the preparation of tools and materials to be used. The oil phase is cetyl alcohol $(0.6 \%)$ mixed with VCO $(20 \%)$, the oil phase is stirred using a hotplate stirrer at $350 \mathrm{rpm}, 55 \mathrm{C}$ for 30 minutes, then the water phase is added, namely methyl paraben $(0.1 \%)$ and propyl paraben $(0.05 \%)$ were dissolved in the remaining distilled water, then heated on a hotplate until completely dissolved, then the solution was cooled. Furthermore, tween $80(30 \%)$ and glycerol of waste cooking oil by-product (7.5\%) were mixed into a solution of methyl paraben and propyl paraben. Then stirred with a magnetic stirrer at $350 \mathrm{rpm}$ for 30 minutes. The water phase is slowly poured into the oil phase by dripping with a spatula. After a while, the mixture was stirred with a magnetic stirrer at 2000-3000 rpm for 8 hours until a thick emulsion was formed, then homogenized with a mixer for 30 minutes and added perfume (oleum rosae) a few drops, then mixed using a mixer until a homogeneous creamy mass was formed. 


\section{RESULTS}

\subsection{Evaluation of Glycerol by-products of waste cooking oil}

\subsubsection{Organoleptic Glycerol}

Evaluation of organoleptic observation data of preparations was carried out during 12 weeks of storage with observations every 1 week, glycerol was stored at room temperature and changes in color, odor and appearance were observed. The results of the evaluation of glycerol stability showed that the color of waste cooking oil glycerol was a thick, odorless and clear white liquid. The results obtained are in accordance with commercial glycerol, which is a thick, odorless and clear white liquid.

\subsubsection{Results Determination Density of Glycerol}

Density is ratio of the weight of the material to its volume at a certain temperature. Density can be used to indicate the purity of a material. The density results show that the density of sample glycerol (waste cooking oil ) is $1.201 \mathrm{~g} / \mathrm{mL}$ and commercial glycerol is $1.276 \mathrm{~g} / \mathrm{mL}$, both density indicate that the density obtained is close to the density of glycerol (pure/theoretical). The standard density value for pure glycerol is $1.267 \mathrm{~g} / \mathrm{mL}$. The results showed that the density of glycerol after the purification process had met the standard.

\subsubsection{Results Determination Viscosity of Glycerol}

Viscosity determination of preparation was carried out using viscometer with number of spindle 2 with $50 \mathrm{rpm}$ speeds and was carried out 1 time. Based on the research, waste cooking oil glycerol showed that the viscosity of waste cooking oil glycerol was $1278 \mathrm{mPa} . \mathrm{s}$. So it meets the requirements of commercial glycerol with viscosity $1410 \mathrm{mPa} . \mathrm{s}$ (SNI, 1995).

\subsubsection{Results Determination of Glycerol Ash Content}

Ash contents describes the amount of inorganic compounds especially metals contained in glycerol and remains behind after the high temperature heating process. The ash content of glycerol of waste cooking oil by-product is $1.036 \%$. The value of ash content according to the quality standard of SNI 06-1564-1995 maximum is $10 \%$. The results showed that the glycerol ash content after the purification process had met the standard.

\subsubsection{Results Determination of Glycerol Water Content}

Water is an unwanted dirt in glycerol because it can reduce the quality and purity of glycerol. The water content of glycerol of waste cooking oil by-product is $3.83 \%$. The value of water content according to the quality standard of SNI 06-1564-1995 maximum is 10\%. The results showed that the water content of glycerol after the purification process had met the standard.

\subsubsection{Result of Fouier Transform Infrared (FTIR) Test}

Results of crude glycerol making was obtained $200.35 \mathrm{~g}$ from $500 \mathrm{~g}$ waste cooking oil , and the purification result after being evaporated with a rotary evaporator was $57.27 \mathrm{~g}$. Glycerol by-product that produced from this research can be proven by FTIR analysis. The result analysis of commercial glycerol as a comparison and the glycerol from transesterification reaction of waste cooking oil using FTIR can be seen in Fig 3.1 and Fig 3.2.

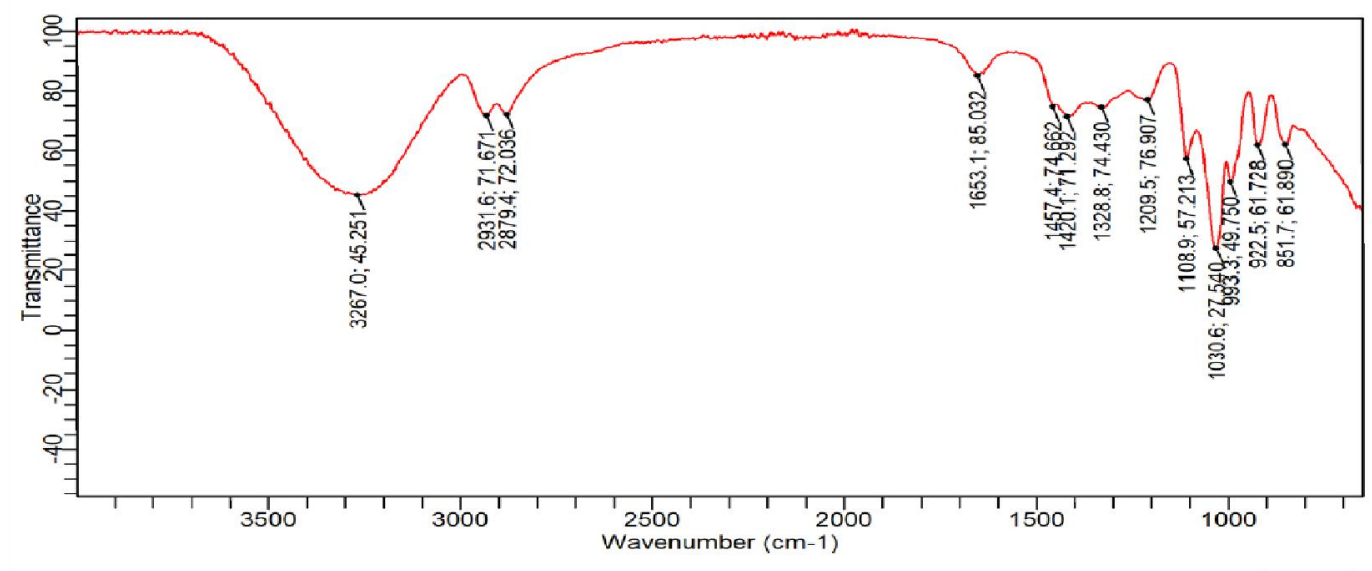




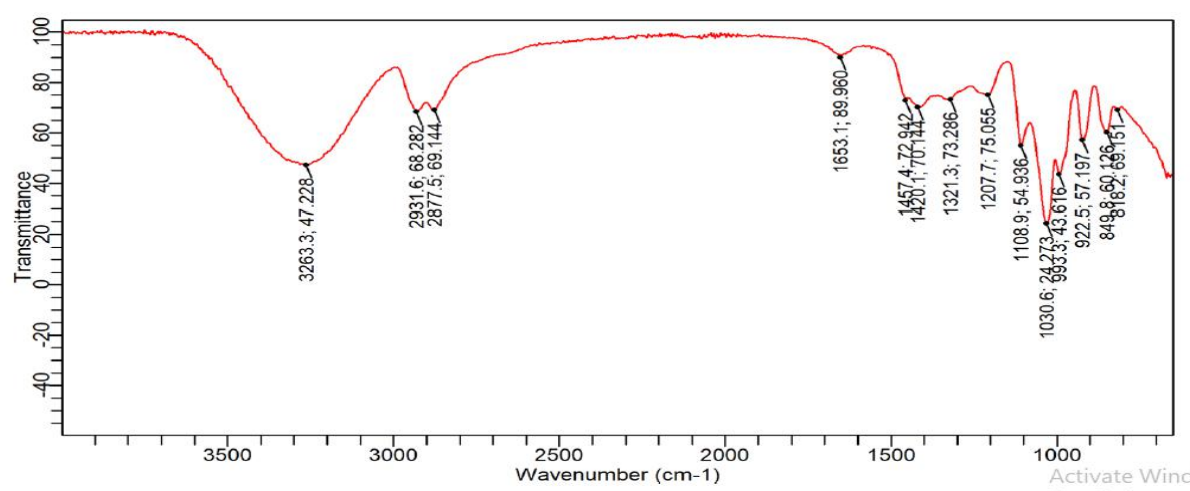

Fig 3.2 FTIR test results of glycerol of waste cooking oil by-product

Analysis of glycerol samples from waste cooking oil showed a wide band at wave number $3263 \mathrm{~cm}^{-}$ ${ }^{1}$ which indicated the presence of OH (hydroxyl) groups. The absorption bands at wave numbers $2931 \mathrm{~cm}^{-1}$ and $2877 \mathrm{~cm}^{-1}$ indicate the presence of $\mathrm{CH}$ aliphatic (alkyl) groups. Then at a wave number of $1653 \mathrm{~cm}^{-1}$ which is $\mathrm{C}=\mathrm{O}$, and an absorption appears around $1300-1000 \mathrm{~cm}^{-1}$ which is the $\mathrm{CO}$ functional group. From the FTIR spectrum, it can be concluded that in the compounds analyzed there are hydroxyl $\mathrm{OH}$ groups, $\mathrm{CH}$ aliphatic, $\mathrm{C}=\mathrm{O}$, and $\mathrm{CO}$ esters which indicate the presence of glycerol. The results of glycerol analysis (commercial) using FTIR showed a wide band at a wave number of $3267 \mathrm{~cm}^{-1}$ which indicated the presence of an $\mathrm{OH}$ (hydroxyl) group. The absorption bands at wave numbers $2931 \mathrm{~cm}^{-1}$ and $2879 \mathrm{~cm}^{-1}$ indicate the presence of $\mathrm{CH}$ aliphatic (alkyl) groups. Then at a wave number of $1653 \mathrm{~cm}^{-1}$ which is $\mathrm{C}=\mathrm{O}$, and an absorption appears around $1300-1000 \mathrm{~cm}^{-1}$ which is the $\mathrm{CO}$ functional group. From the FTIR spectrum of glycerol by-products from waste cooking oil and pure glycerol, it can be concluded that in the glycerol compound obtained from waste cooking oil there are $\mathrm{OH}$ (hydroxyl), $\mathrm{CH}$ aliphatic, $\mathrm{C}=\mathrm{O}$, and $\mathrm{CO}$ groups which indicate that glycerol is present. Forms of commercial glycerol and waste cooking oil glycerol can be seen in Fig 3.3.

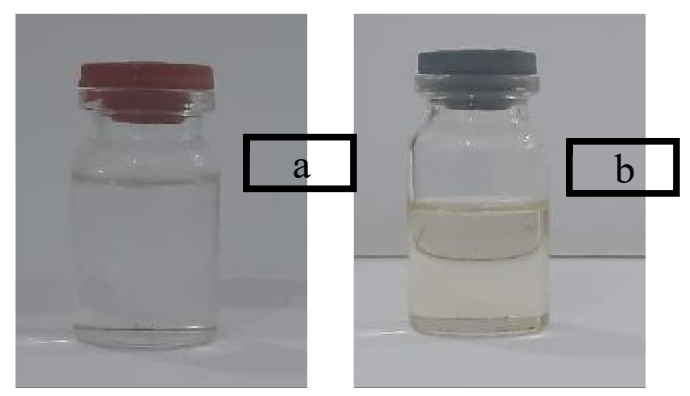

Fig 3.3 commercial glycerol (a) and glycerol of waste cooking oil by-product (b)

\subsection{Results of Nanocream Preparation}

Nanocream preparation tween 80 and glycerol cosurfactant from waste cooking oil, with optimum concentration of surfactant (Tween 80) 30\% and cosurfactant (glycerol) 7,5\% produces thick and white nanocream. This is because the concentration of surfactant and cosurfactant used is sufficient to form a protective layer that prevents the incorporation of the droplets of the inner phase. VCO is used in this formulation as a carrier oil with $20 \%$ concentration, and cetyl alcohol as an emollient as well as a consistency enhancer with $0.6 \%$ concentration to produce nanocream with thickness and white consistency. The results of the nanocream formulation with various concentration of glycerol from waste cooking oil can be seen in Fig 3.4

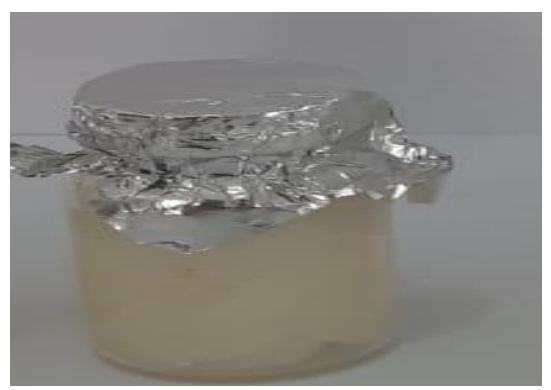


Fig 3.4 Nanocream preparation of glycerol cosurfactant from waste cooking oil

Measurement of nanocream particles, aims to determine the particle size of the VCO nanocream formula and glycerol cosurfactant from waste cooking oil. Particle measurements were carried out using the FRITSCH Analysette 2.2 Nanotech. The particle size data of nanocream from waste cooking oil glycerol with $7.5 \%$ concentration showed that the preparation had a particle size between the required range of nanocream size. The requirements for nanocream preparations semisolid that have a requirement range of size 20-500 nm (Abdulkarim et al., 2010). The particle size distribution of nanocream preparations from waste cooking oil shows that the particle size obtained is $397.76 \mathrm{~nm}$. The results of the particle size of the preparations obtained have met the standard particle size of semi-solid preparations, and glycerol from waste cooking oil is able to function as a cosurfactant by helping surfactants in reducing the surface tension between the oil phase and the water phase so that it plays a very important role in the nanocream produced. The results of the particle size of the preparation can be seen in Figure 3.5

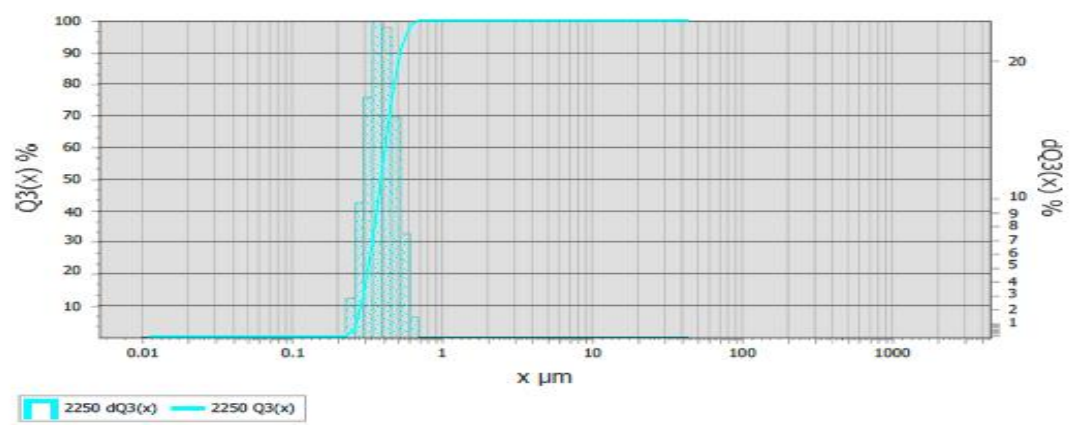

Fig 3.5 Particle Size of Nanocream Preparatio

\section{CONCLUSION}

Based on the results of this research, it can be concluded that glycerol from waste cooking oil has physical and chemical properties including a thick and clear white liquid, density $1.201 \mathrm{~g} / \mathrm{mL}$, viscosity 1278 mPa.s, water content $3.83 \%$, ash content $1.036 \%$. Based on the IR spectrum, the glycerol by-product of waste cooking oil showed the presence of $\mathrm{C}=\mathrm{O}$ carbonyl groups, $\mathrm{CO}$ esters, $-\mathrm{OH}$ and $\mathrm{CH}$ aliphatic which were similar to commercial glycerol. The results of formulation of nanocream preparation with $30 \%$ (Tween 80) concentration as surfactant and cosurfactant (glycerol) 7,5\%, VCO $20 \%$ as carrier oil, and cetyl alcohol as emollient also increased consistency with $0,6 \%$ concentration to produce nanocream with thickness and white consistency and has a particle size $397.76 \mathrm{~nm}$. The requirements for nanocream preparations semisolid that have a requirement range of size $20-500 \mathrm{~nm}$. So it can be concluded that glycerol as a by-product of waste cooking oil has a functional group similar to commercial glycerol and can function as a cosurfactant to form nanocream preparations with particle sizes that still meet the requirements in semi-solid preparations.

\section{REFERENCES}

[1] Abdulkarim, M. F., Abdullah, G. Z., Chitneni, M., Mahdi, E. S., Yam, M. F., Faisal, A. (2010). Formulation and Characterization of Palm Oil Esters Based Nanocream for Topical Delivery of Piroxicam. International Journal of DrugDelivery. $2: 287-298$.

[2] AOAC. (1995). Meth Official Methods of Analysis of The Association of Analytical Chemists. Washington D.C.

[3] Appleby, D.B, (2005). Gliserol on The Biodiesel Handbook. AOCS Press.

[4] Arita, S., Dara, M. B., \& Irawan, J. (2008). Making Fatty Acid Methyl Esters from Cpo Off Grade With Esterification-Transesterification Method. Journal of Chemical Engineering, 15(2), 34-43.

[5] Aziz, I. (2007). Kinetic Transesterification Reaction of Waste cooking oil . Journal of Chemistry VALENSI, 1(1), $19-23$.

[6] Aziz, I., Nurbayti, S., \& Luthfiana, F. (2008). Purification of Glycerol from Biodiesel Making By-Product Using Waste cooking oil as Raw Material. Journal of Chemistry VALENSI, 1(3). 
[7] Aziz, I., Nurbayti, S., \& Suwandari, J. (2013). Making Glycerol With Hydrolysis Reaction of Waste cooking oil . Chemistry Progress, 6(1).

[8] Ditjen POM RI. (1995). Indonesian Pharmacopoeia. Edisi IV. Jakarta: Department of Health of Republic of Indonesia.

[9] Hermanto, V.C. (2016). Making Kojic Acid Dipalmitate Nanocream With Combination of Surfactant Tween 80 and Cosurfactant Polyethylene Glicol 400 Using Mixer. Thesis. Faculty of Pharmacy. Sanata Dharma University. Yogyakarta.

[10] Julianus, D. (2006). Optimization of Biodiesel Making Process from Waste cooking oil . Department of Chemical Engineering, UKI Paulus, Makassar

[11] Kaplan, A.B. H., Cetin, M., Orgul, D., Hacimufnewlu, A., dan Hekimoglu, S. (2019). Formulation and In Vitro Evaluation of Topical Nanoemulsion based Gels Containing Daidzein. Journal of Drug Delivery Science and Technology (19) : 30263.

[12] M. Pagliaro dan M. Rossi. (2008). The Future of Glycerol: New Uses of a Versatile Raw Material. RSC Green Chemistry Book Series.

[13] Priani, S. E., Wulan, K., Amila, G. (2018). Formulation of Microemulsion Preparation Anti-Acne Gel Contains a Combination of Black Cumin Oil and Olive Oil. Scientific Journal of Pharmacy. Pharmacy Study Program, Islamic University of Bandung (UNISBA), Bandung.

[14] SNI (1995). Standarisasi Nasional Indonesia. SNI 06-1564-1995: Crude Glycerol. National Standardization Council. Jakarta.

[15] Suhery, W., Mira, F., dan Ivone, P. (2018). Formulation of Microemulsion from Combination of Pure Coconut Oil and Rice Bran Oil as Hair Fertilizer. Traditional Medicine Journal. Riau Collage of Pharmacy.

[16] Wijaya, S., Arthawan, A.I., dan Sari, A.Novita. (2012). Potential of Coconut Sap as Bioethanol Raw Material. Bumi Lestari Journal. Vol. 12. No. 1. Department of Agricultural Engineering. Udayana University.

[17] Wardana, D., Ahmad, R., Dinda, P. dan Ediyanto. (2019). Utilization of Glycerol from Used Oil as Ester Glycerol Surfactant. IJCST UNIMED. Department of Chemistry FMIPA. Medan. 